\title{
Clinicopathologic features of gastric cancer with synchronous and metachronous colorectal cancer in Korea: are microsatellite instability and p53 overexpression useful markers for predicting colorectal cancer in gastric cancer patients?
}

\author{
Hee Jin Kim ${ }^{1,4}$ - Nayoung Kim ${ }^{1}$ Yoon Jin Choi $^{1} \cdot$ Hyuk Yoon $^{1} \cdot$ Cheol Min Shin ${ }^{1}$ • \\ Young Soo Park ${ }^{1} \cdot$ Hye Seung Lee ${ }^{2}$ Sang-Hoon Ahn ${ }^{3} \cdot$ Do Joong Park ${ }^{3} \cdot$ \\ Hyung Ho $\mathrm{Kim}^{3} \cdot$ Il Tae $\mathrm{Son}^{3} \cdot$ Sung-Bum Kang ${ }^{3}$. Dong Ho Lee ${ }^{1}$ \\ Received: 30 May 2015/Accepted: 22 September 2015/Published online: 7 October 2015 \\ (c) The International Gastric Cancer Association and The Japanese Gastric Cancer Association 2015
}

\begin{abstract}
Background A large-scale study was performed to identify the risk factors for developing synchronous and metachronous colorectal cancer (CRC) in gastric cancer (GC) patients, including microsatellite instability (MSI) and $\mathrm{p} 53$ overexpression.

Methods A total of $1041 \mathrm{GC}$ patients who underwent endoscopic resection or surgery and underwent colonoscopy simultaneously or during surveillance for GC were consecutively enrolled. Clinicopathologic characteristics, MSI, and p53 overexpression were compared between the GC patients with and those without synchronous and metachronous CRC.

Results Of the 1041 patients, CRCs were detected in 67 (6.4\%) patients with GC. Forty-six (4.4\%) had synchronous CRC and $21(2.0 \%)$ had metachronous CRC. Univariate analysis indicated that age $\geq 63$ years $(P<0.001)$, male sex $(P=0.005)$, and p53 overexpression $(P=0.040)$ were significantly associated with a higher incidence of CRC. However, body mass index, smoking, tumor location, tumor multiplicity, tumor histology, TNM stage, and MSI were not significantly
\end{abstract}

Nayoung Kim

nayoungkim49@empal.com; nayoungkim49@empas.com

1 Department of Internal Medicine, Seoul National University Bundang Hospital, 82, Gumi-ro 173 Beon-gil, Bundang-gu, Seongnam-si, Gyeonggi-do 13620, South Korea

2 Department of Pathology, Seoul National University Bundang Hospital, Seoungnam, South Korea

3 Department of Surgery, Seoul National University Bundang Hospital, Seoungnam, South Korea

4 Department of Internal Medicine, Myongji Hospital, Goyang, South Korea associated with the incidence of CRC. Age $\geq 63$ years (OR: 5.881; $95 \%$ CI: 3.083-11.221; $P<0.001)$ and male sex (OR: 2.933 ; $95 \%$ CI: $1.307-6.584 ; P=0.009$ ) were risk factors for CRC in GC patients according to multivariate analysis.

Conclusions GC patients who are male and/or $\geq 63$ years old are recommended to receive colonoscopy to detect CRC. MSI and p53 overexpression were not useful molecular markers for predicting CRC in GC.

Keywords Gastric cancer - Colorectal cancer . Microsatellite instability $\cdot$ p53

\section{Introduction}

Due to recent advances in diagnostic techniques and treatment modalities, the overall survival rate of gastric cancer (GC) patients has significantly improved. Their prolonged survival has resulted in an increased chance of a second primary malignancy in GC patients. Therefore, it is important to recognize the characteristics of these patients with multiple primary malignancies in order to detect and hopefully cure the second primary malignancy as early as possible.

Previous studies have demonstrated that 3.4-5.9\% of patients with GC have a secondary primary cancer, and colorectal cancer (CRC) is the most commonly diagnosed secondary primary cancer in patients with GC [1-4]. In previous studies of synchronous CRC that was screened for using colonoscopy in GC patients, $2-5 \%$ of patients were found to have second primary CRCs, depending on the patient's election criteria and the time of colonoscopy [5-9]. Those studies emphasized the importance of screening colonoscopy for patients diagnosed with GC, but guidelines 
for screening for $\mathrm{CRC}$ in patients with $\mathrm{GC}$ have not been established yet.

GC is the most common extracolonic malignancy associated with Lynch syndrome (previously referred to as hereditary nonpolyposis colorectal cancer) after endometrial and ovarian cancer [10]. The mechanisms underlying the development of GC and CRC remain unclear. GC arises not only from the combined effects of environmental factors [Helicobacter pylori (H. pylori) infection, consumption of salted and nitrated foods, and smoking] and genetic susceptibility factors but also from the accumulation of genetic and epigenetic alterations that play crucial roles in the process of cellular tumorigenesis. H. pylori infection plays a major role in gastric carcinogenesis, with geographic differences. Worldwide, the incidence of GC is high in countries with a high prevalence of $H$. pylori infection; the prevalence of $H$. pylori infection among patients with GC is also significantly higher than that in normal control patients [11]. Sporadic CRC arises through the aggregate effects of multiple genetic mutations and epigenetic alterations involving genes that regulate cell growth and differentiation, and there are distinct mechanisms for sporadic CRC: chromosomal instability (CIN) by activation of oncogenes and inactivation of tumor suppressor genes, microsatellite instability (MSI) by inactivation of a DNA mismatch repair gene, and the serrated pathway [12]. Dietary factors such as low intake of fruit, vegetables, or fiber and high intake of red meat, saturated fat, or alcohol as well as lifestyle factors including lack of exercise, smoking, and obesity are known to be associated with an increased risk of CRC [13]. Considering the pathogenesis of $\mathrm{GC}$ and $\mathrm{CRC}$, possible reasons for the association between GC and CRC could be an overall greater predisposition to cancer due to the similar environmental and genetic factors that contribute to these two cancers. In previous investigations of colorectal neoplasm (colorectal adenoma or cancer) in GC patients compared with those in healthy controls, the number of patients with $\mathrm{GC}$ was too small to allow significant risk factors for CRC to be identified.

Thus, we conducted the study reported in the present paper to compare GC patients with $\mathrm{CRC}$ to GC patients without $\mathrm{CRC}$ in order to determine the risk factors for developing $\mathrm{CRC}$ in GC. We enrolled a large number of patients for the study and evaluated whether MSI and p53 overexpression are suitable genetic markers for predicting the risk for CRC in GC.

\section{Materials and methods}

Medical records of 1041 patients with GC who underwent endoscopic resection or surgery and received colonoscopy simultaneously or during the follow-up period at Seoul
National University Bundang Hospital between June 2003 and December 2013 were retrospectively reviewed. Concurrent colonoscopy for GC patients has not been routinely applied in our center. Patients were excluded if they met more than one of the following criteria: (1) past history of gastric or colorectal cancer; (2) past history of gastric or colorectal resection; (3) family history of $\mathrm{CRC}$ in firstdegree relatives; (4) familial adenomatous polyposis; (5) inflammatory bowel disease. This study was approved by the institutional review board of Seoul National University Bundang Hospital (IRB number: B-1504-296-116).

Personal history was also acquired by reviewing medical records of smoking consumption habits, comorbidities such as diabetes mellitus and hypertension, any history of any other primary malignancy, any family history of GC in first-degree relatives, and any history of $H$. pylori eradication therapy. As all of the patients had already been enrolled through other cohort studies, this history was easily acquired. The patients were classified into those who had never smoked, past smokers, and current smokers according to their smoking histories for the previous 6 months. Their height and weight were checked at the time of endoscopy, and their body mass index (BMI) was computed as the weight in kilograms per square surface area in square meters $\left(\mathrm{kg} / \mathrm{m}^{2}\right)$. According to the International Obesity Task Force criteria for the Asia-Pacific population, BMI scores were classified as follows: normal $(<23)$, overweight $(\geq 23$ and $<25)$, or obese $(\geq 25)$ [14]. The location, size, histologic features of the tumor, and TNM stage defined according to the 7th edition of the AJCC Cancer Staging Manual were determined [15]. In patients who underwent surgical resection, $\mathrm{T}$ and $\mathrm{N}$ classification were assessed based on the final pathological result, and $\mathrm{M}$ classification was determined by surgical findings or computed tomography (CT) results. In patients who underwent endoscopic resection, $\mathrm{T}$ classification was based on the final pathologic results and $\mathrm{N}$ and $\mathrm{M}$ classification on the CT findings. Early gastric cancer (EGC) was defined as a tumor that was confined to the mucosa or submucosa regardless of lymph node (LN) involvement. Advanced gastric cancer (AGC) was defined as a tumor that invaded the proper muscle or beyond. Synchronous CRC was defined as a CRC that was diagnosed within 6 months before or after GC detection, while metachronous $\mathrm{CRC}$ was defined as a CRC that was detected more than 6 months after GC.

Helicobacter pylori infection status was determined by modified Giemsa staining, culture, rapid urease testing (CLOtest, Delta West, Bentley, Australia), and serum IgG specific for $H$. pylori, which were measured by an enzymelinked immunosorbent assay (Genedia $H$. pylori ELISA; Green Cross Medical Science Corp., Eumsung, South Korea). If any of these tests aside from serology gave a 
positive result, the patient was judged to be currently infected with $H$. pylori. Only when all of the test results were negative and there was no history of $H$. pylori eradication was the patient considered to be negative.

To test for MSI, tumor DNA was extracted from paraffin-embedded tumor tissues from individual patients. Normal DNA was extracted from the surrounding normal tissue. Five microsatellite markers (BAT-25, BAT-26, D2S123, D5S346, and D17S250), recommended by a National Cancer Institute (NCI) workshop on MSI, were used to analyze paired normal and tumor DNA [16]. Polymerase chain reaction (PCR) was performed using a DNA autosequencer (ABI 3730 genetic analyzer; Applied Biosystems, Foster City, CA, USA). The shift of PCR products from tumor DNA was compared to that of DNA from normal mucosa. The size of each fluorescent PCR product was calculated using GeneMapper software (Applied Biosystems). Based on the guidelines of the NCI, cases positive for $\geq 2$ markers were considered to show high-frequency MSI (MSI-H), while cases positive for $<2$ markers were considered to show low-frequency MSI (MSI-L), and cases with no MSI were defined as microsatellite stable (MSS) [16, 17].

We investigated the overexpression of p53 protein via immunohistochemistry. Sections $4 \mu \mathrm{m}$ thick were cut from each cancer tissue block and then deparaffinized and dehydrated. Immunohistochemical staining was performed using an automatic immunostainer (BenchMark ${ }^{\circledR}$ XT, Ventana Medical Systems Inc., Tucson, AZ, USA) according to the manufacturer's instructions. The primary antibody used was mouse monoclonal antibody for p53 (DO7, Dako, Carpinteria, CA, USA). A positive result corresponded to staining of $10 \%$ or more of the tumor cell nuclei [18].

All statistical analyses were performed using SPSS software, version 20.0 (SPSS Inc., Chicago, IL, USA). Categorical variables were analyzed using the chi-square test and continuous variables by Student's $t$-test. Fisher's exact test was used when the sample size was small. For continuous variables such as age, a receiver operating characteristic (ROC) curve was used to acquire a cutoff value for stratification. Logistic regression analysis was performed to identify the risk factors for CRC. Odds ratios (ORs) and $95 \%$ confidence intervals (CIs) were used to describe associations. A $P$ value of $<0.05$ was considered statistically significant.

\section{Results}

A total of 1041 patients with GC were analyzed in the present study. There were 762 males $(73.2 \%)$ and 279 females $(26.8 \%)$, and the median age of all patients was
59.66 years (range $27-89$ years). Eight hundred ninety-one patients $(85.6 \%)$ underwent surgical resection and 150 patients $(14.4 \%)$ were treated using endoscopic resection. CRCs were detected in $67(6.4 \%)$ GC patients simultaneously or during the follow-up period; 46 (4.4\%) GC patients had synchronous CRC and 21 (2.0\%) had metachronous CRC (Fig. 1). Among these 67 patients with both GC and CRC, none had a clinical diagnosis of Lynch syndrome. The time interval between GC and metachronous CRC ranged from 7 to 106 months, with an average of 28.5 months. Among the GC patients with metachronous CRC, $7(33.3 \%)$ patients were diagnosed within 12 months, $15(71.4 \%)$ patients were diagnosed within 36 months, and $18(85.7 \%)$ patients were diagnosed within 60 months after diagnosis of GC.

Table 1 shows the characteristics of CRC in the GC patients included in the present study. Over the half of the synchronous and metachronous CRCs were early-stage disease (TNM stage 0 or I or II). Forty-nine (73.1\%) CRCs were located in the distal colon or rectum, and $61(91.0 \%)$ CRCs had well or moderately differentiated adenocarcinoma. Only four of the CRCs had MSI-H, and the corresponding patients were all $>73$ years old.

As shown in Table 2, GC patients were divided into two groups according to the presence or absence of CRC, and the clinicopathologic characteristics of the two groups were compared. The mean age of the GC patients with CRC was $66.76 \pm 10.40$ and the mean age of the GC patients without CRC was $59.18 \pm 11.42$ years $(P<0.001)$. When the cutoff value was obtained from the ROC curve in order to divide the patients into age-based groups, the optimal cutoff age for predicting CRC was found to be 62.5 years (with a sensitivity of $80.5 \%$ and a specificity of $58.3 \%$; AUC: 0.711 ). When univariate analysis was performed for an age of 63 years old, the incidence of patients $\geq 63$ years old was $80.6 \%$ among the GC patients with CRC, which was significantly different $(P<0.001)$ from the incidence of patients $\geq 63$ years old (41.7\%) observed among the GC patients without CRC. There was a significantly higher proportion of males among the GC patients with CRC than among the GC patients without CRC (88.1 vs. $72.2 \%, P=0.005$ ). However, other clinicopathologic characteristics such as smoking history, BMI, histology, and TNM stage did not differ between the GC patients with CRC and those without CRC.

Among all 1041 patients, 792 were examined by routine MSI testing. In these patients, there were $62(7.8 \%)$ with MSI-H. The proportion of the patients with MSI-H GC was not significantly different between the GC patients with and without CRC (8.1 vs. $7.8 \%, P=0.810$ ) Overexpression of p53 was evaluated in 975 patients, and p53 overexpression was more frequently observed in GC patients with CRC than in GC patients without CRC (55.6 vs. $42.3 \%, P=0.040$ ). 
Fig. 1 Flow chart of the study. $G C$ gastric cancer, $C R C$ colorectal cancer. *Tumor invades the muscularis propria layer or deeper

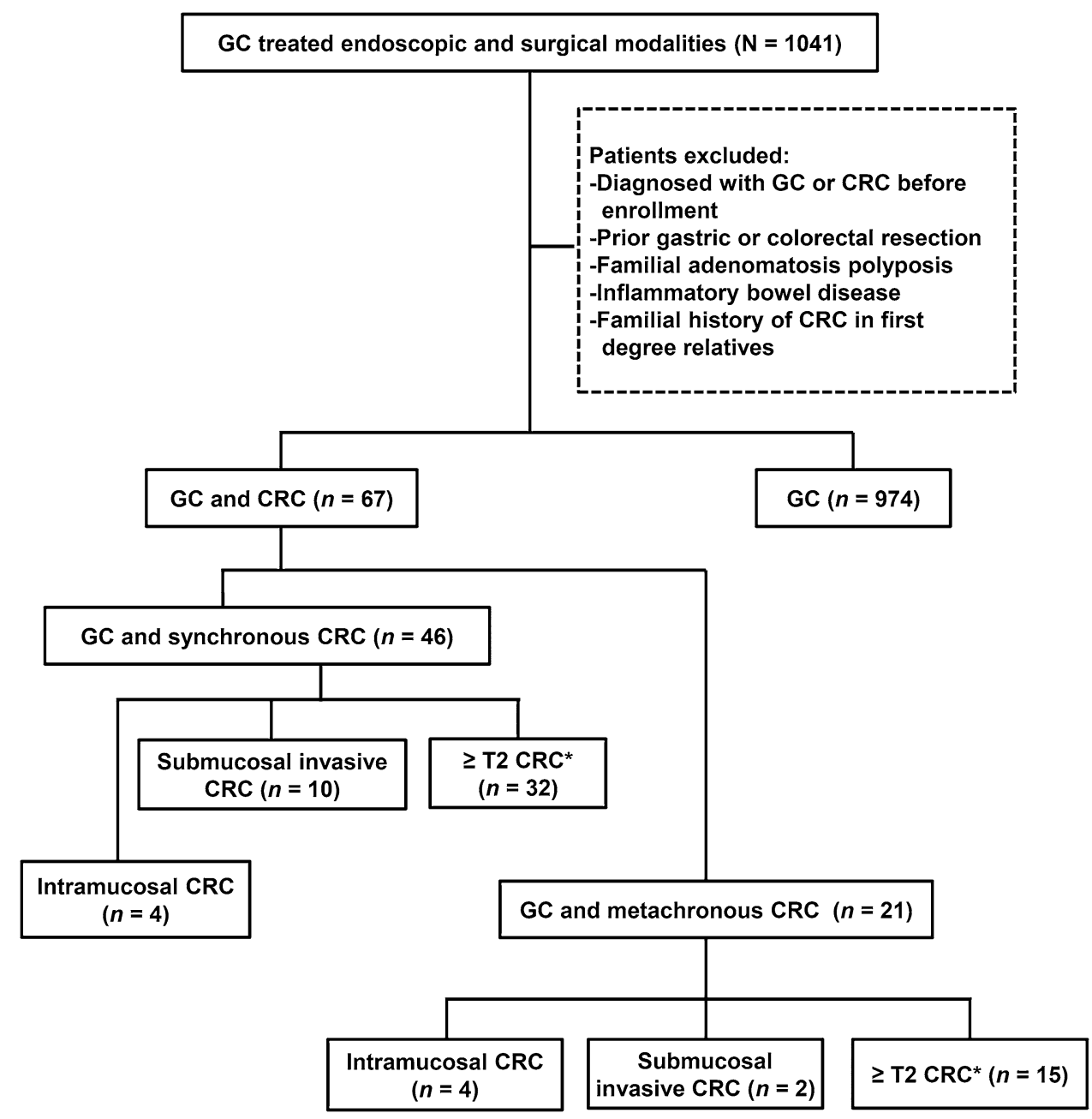

Only 180 patients who gave their consent to be tested for H. pylori in a related study (IRB B-1011/115-005) underwent all of the diagnostic tests for $H$. pylori infection status and were surveyed for a history of $H$. pylori eradication (Table 3). Based on this small number of patients, negative H. pylori infection status was found to be more frequent in GC patients with CRC, but the frequency of negative $H$. pylori infection status did not differ significantly between the GC patients with and without CRC (30.0 vs. $11.2 \%$, $P=0.108)$.

Among the factors that were shown to have a significant association with CRC by univariate analysis, age $\geq 63$ years old (OR: 5.881; $95 \%$ CI: 3.083-11.221; $P<0.001)$ and male sex (OR: 2.933; $95 \%$ CI: 1.307-6.584; $P=0.009$ ) were found to be significantly and independently associated with the development of CRC in GC by multivariate analysis (Table 4). Overexpression of p53 was not a significant risk factor for CRC in GC patients (OR: 1.392; $95 \%$ CI: 0.821-2.361; $P=0.220)$. H. pylori infection status was not included in the multivariate analysis because of the small number of patients who were evaluated for $H$. pylori infection status.

In addition, tumor histology was not a significant risk factor for CRC in patients with intestinal-type GC or diffuse-type GC (data not shown).

\section{Discussion}

The current study was designed to identify patients with $\mathrm{GC}$ who are at high risk of developing CRC. The incidence of $\mathrm{CRC}$ in the patients with $\mathrm{GC}$ was $6.4 \%$ and the prevalence of synchronous CRC in GC patients was $4.4 \%$. Previous reports have revealed that GC patients present significantly higher frequencies of colorectal adenoma and carcinoma than the general population. The reported prevalence of $\mathrm{CRC}$ in the patients with $\mathrm{GC}$ ranged from 2 to $5 \%$ [5-9], while an Asian multinational survey showed that the prevalence of CRC in the general population was $1.0 \%$ [19]. In the present study, $2.0 \%$ of all GC patients 
Table 1 Characteristics of synchronous and metachronous colorectal cancer in the gastric cancer patients

\begin{tabular}{ll}
\hline & Number of patients \\
\hline Location & \\
Proximal colon & $18(26.9)$ \\
Distal & $31(46.2)$ \\
Rectum & $18(26.9)$ \\
Histology & \\
WD or MD & \\
PD & $61(91.0)$ \\
SRC & $4(6.0)$ \\
Mucinous & $1(1.5)$ \\
Lymphovascular invasion & $1(1.5)$ \\
Absent & \\
Present & \\
No data & $40(60.6)$ \\
TNM stage & $26(39.4)$ \\
O & 1 \\
I &
\end{tabular}

The data in parentheses are percentages

$W D$ well differentiated, $M D$ moderately differentiated, $P D$ poorly differentiated, $S R C$ signet ring cell carcinoma, MSI microsatellite instability, MSS microsatellite stable

had metachronous CRC, and nearly all of these CRCs $(85.7 \%)$ occurred within 5 years after the diagnosis of GC. Though there are no detailed screening strategies for CRC after a diagnosis of GC, based on our reports, it is also important to screen for CRC when GC is diagnosed or during follow-up so that the second cancer can be detected early enough to allow curative treatment.

In the present study, age $\geq 63$ years old was significantly and independently associated with the development of CRC in patients with GC. Because cancer incidence tends to increase with age and CRC is more prevalent in males
[20], the high incidence of CRC in elderly patients and males was not surprising. According to previous studies, male sex [6,21], age $\geq 50$ years old [21], and smoking [6] were significantly associated with colorectal neoplasm (colorectal adenoma and cancer). A recent Japanese study including $1891 \mathrm{GC}$ patients demonstrated that the prevalence of synchronous CRC in patients with GC was $3.2 \%$, and that multiple GC, anemia, and smoking history were risk factors for CRC in GC patients [5]. However, patients with a family history of CRC were also included in this study [5] and other studies [6, 8, 9]. Among all types of cancer, patients with CRC are the third most likely to have a family member with a history of the same type of cancer (nearly $13 \%$ of CRC patients have a family member with a history of concordant cancer) [22]. Although we included a smaller number of patients with GC than the number included in a recent Japanese study [5], patients with a family history of CRC in first-degree relatives were excluded, and our study comprehensively analyzed interesting issues such as the relationship between CRC and GC with regard to MSI, overexpression of $\mathrm{p} 53$, and $H$. pylori infection status.

The mechanism underlying the development of concurrent GC and CRC remains controversial. One explanation could be the same genetic alterations in GC and CRC, such as APC, p53, DCC, and K-ras [23-29]. Additionally, MSI is thought to play an important role in gastric and colorectal carcinogenesis [30]. Thus, MSI and p53 were evaluated in the present study.

MSI is caused by impairment of the DNA mismatch repair (MMR) system. In sporadic CRC, DNA MMR deficiency is acquired mainly as a consequence of epigenetic transcriptional silencing of MLH1 via hypermethylation of its promoter [31]. DNA methylation is an agerelated phenomenon and MSI-H sporadic CRCs are more frequent in the elderly [32]. In GC, the frequency of MSI has been reported as $8-37 \%$, depending on the cases and the number of markers examined [33, 34], and some reports indicate that patients with GC with MSI show an increased risk for developing double primary cancer [3, 35]. Previous studies on the development of CRC in GC patients did not assess MSI status. As far as we are aware, this study is the first to address the issue of whether MSI is a useful marker for predicting synchronous and metachronous CRC in GC. Disappointingly, MSI-H was not significantly associated with the development of CRC in GC. There could be two reasons for the lack of a significant association between MSI-H and CRC development in GC. In our study, $7.8 \%$ of GC patients showed MSI-H, which is lower than the corresponding percentages reported in other studies [33]; however, the number of GC patients with MSI-H in the present study was relatively small. Furthermore, the carcinogenic pathways differ for GC and 
Table 2 Comparison of clinicopathologic characteristics between gastric cancer patients with synchronous and metachronous colorectal cancer and those without colorectal cancer

\begin{tabular}{|c|c|c|c|}
\hline Characteristic & $\begin{array}{l}\text { Without colorectal } \\
\text { cancer }(n=974)\end{array}$ & $\begin{array}{l}\text { With synchronous or metachronous } \\
\text { colorectal cancer }(n=67)\end{array}$ & $P$ value \\
\hline Age (years, mean $\pm \mathrm{SD}$ ) & $59.18 \pm 11.42$ & $66.76 \pm 10.40$ & $<0.001$ \\
\hline$<63$ & $568(58.3)$ & $13(19.4)$ & $<0.001$ \\
\hline$\geq 63$ & $406(41.7)$ & $54(80.6)$ & \\
\hline Male & $703(72.2)$ & 59 (88.1) & 0.005 \\
\hline Body mass index $\left(\mathrm{kg} / \mathrm{m}^{2}\right)$ & & & 0.967 \\
\hline$<23$ & $392(40.2)$ & $27(40.3)$ & \\
\hline$\geq 23$ or $<25$ & $245(25.2)$ & $16(23.9)$ & \\
\hline$\geq 25$ & 337 (34.6) & $24(35.8)$ & \\
\hline Current/past smoker & $398(40.9)$ & $25(37.3)$ & 0.567 \\
\hline Diabetes mellitus & $127(13.0)$ & $13(19.4)$ & 0.140 \\
\hline Hypertension & $290(29.8)$ & $26(38.8)$ & 0.120 \\
\hline Other primary malignancy & $27(2.8)$ & $3(4.5)$ & 0.435 \\
\hline Family history of gastric cancer & $133(13.7)$ & $5(7.5)$ & 0.148 \\
\hline Location & & & 0.684 \\
\hline Upper & $141(14.5)$ & $10(14.9)$ & \\
\hline Middle & $218(22.4)$ & $19(28.4)$ & \\
\hline Lower & $593(60.9)$ & $37(55.2)$ & \\
\hline Diffuse & $22(2.3)$ & $1(1.5)$ & \\
\hline \multicolumn{4}{|l|}{ Tumor size $(\mathrm{mm}$, mean $\pm \mathrm{SD})$} \\
\hline$<40$ & $652(67.1)$ & $39(58.2)$ & 0.137 \\
\hline$\geq 40$ & $320(32.9)$ & $28(41.8)$ & \\
\hline No data & 2 & 0 & \\
\hline Multiplicity of gastric cancer & & & 0.129 \\
\hline Single & $927(95.5)$ & $61(91.0)$ & \\
\hline Multiple & $44(4.5)$ & $6(9.0)$ & \\
\hline No data & 3 & 0 & \\
\hline Histology & & & 0.654 \\
\hline WD, MD & $546(56.1)$ & $41(61.2)$ & \\
\hline $\mathrm{PD}, \mathrm{SRC}$ & $404(41.5)$ & $24(35.8)$ & \\
\hline Others & $24(2.5)$ & $2(3.0)$ & \\
\hline Lauren's classification & & & 0.260 \\
\hline Intestinal & $589(60.7)$ & $44(67.7)$ & \\
\hline Diffuse or mixed & $382(39.3)$ & $21(32.3)$ & \\
\hline No data & 3 & 2 & \\
\hline Lymphovascular invasion & & & 0.264 \\
\hline Yes & $327(33.6)$ & $27(40.3)$ & \\
\hline No & $646(66.4)$ & $40(59.7)$ & \\
\hline No data & 1 & 0 & \\
\hline EGC/AGC & & & 0.301 \\
\hline EGC & 746 (76.6) & $55(82.1)$ & \\
\hline AGC & $228(23.4)$ & $12(17.9)$ & \\
\hline $\mathrm{T}$ stage & & & 0.142 \\
\hline $\mathrm{T} 1$ & $654(67.1)$ & $43(64.2)$ & \\
\hline $\mathrm{T} 2$ & $92(9.4)$ & $12(17.9)$ & \\
\hline $\mathrm{T} 3$ & $122(12.5)$ & $6(9.0)$ & \\
\hline $\mathrm{T} 4$ & $106(10.9)$ & $6(9.0)$ & \\
\hline
\end{tabular}


Table 2 continued

\begin{tabular}{|c|c|c|c|}
\hline Characteristic & $\begin{array}{l}\text { Without colorectal } \\
\text { cancer }(n=974)\end{array}$ & $\begin{array}{l}\text { With synchronous or metachronous } \\
\text { colorectal cancer }(n=67)\end{array}$ & $P$ value \\
\hline $\mathrm{N}$ stage & & & 0.986 \\
\hline No & 669 (68.7) & 46 (68.7) & \\
\hline N1 & $106(10.9)$ & 8 (11.9) & \\
\hline N2 & $83(8.5)$ & $5(7.5)$ & \\
\hline N3 & $116(11.9)$ & 8 (11.9) & \\
\hline M stage & & & 0.180 \\
\hline M0 & 954 (97.9) & $64(95.5)$ & \\
\hline M1 & $20(2.1)$ & $3(4.5)$ & \\
\hline Stage & & & 0.383 \\
\hline I & $667(68.5)$ & $49(73.1)$ & \\
\hline II & $129(13.2)$ & $6(9.0)$ & \\
\hline III & $158(16.2)$ & $9(13.4)$ & \\
\hline IV & $20(2.1)$ & $3(4.5)$ & \\
\hline MSI & & & 0.810 \\
\hline MSS/MSI-L & $673(92.2)$ & 57 (91.9) & \\
\hline MSI-H & $57(7.8)$ & $5(8.1)$ & \\
\hline No data & 244 & 5 & \\
\hline p53 overexpression & & & 0.040 \\
\hline Positive & $386(42.3)$ & $35(55.6)$ & \\
\hline Negative & $526(57.7)$ & $28(44.4)$ & \\
\hline No data & 62 & 4 & \\
\hline
\end{tabular}

Numbers in bold type indicate statistical significance

Data in parentheses are percentages

$S D$ standard deviation, $W D$ well-differentiated, $M D$ moderately differentiated, $P D$ poorly differentiated, $S R C$ signet ring cell carcinoma, $E G C$ early gastric cancer, $A G C$ advanced gastric cancer, $M S I$ microsatellite instability, MSS microsatellite stable

Table 3 Comparison of Helicobacter pylori infection status between gastric cancer patients with synchronous and metachronous colorectal cancer and those without colorectal cancer

\begin{tabular}{llll}
\hline $\begin{array}{l}H . \\
\text { pylori } \\
\text { infection }\end{array}$ & $\begin{array}{l}\text { Without } \\
\text { colorectal } \\
\text { cancer } \\
(n=170)\end{array}$ & $\begin{array}{l}\text { With synchronous or } \\
\text { metachronous colorectal } \\
\text { cancer }(n=10)\end{array}$ & $P$ value \\
\hline Present & $151(88.8)$ & $7(70.0)$ & 0.108 \\
Absent & $19(11.2)$ & $3(30.0)$ & \\
\hline
\end{tabular}

Data in parentheses are percentages

CRC. Most CRCs follow the classical adenoma-carcinoma sequence [23], which is commonly accompanied by the CIN pathway, and approximately $15 \%$ of sporadic CRCs acquire genetic alterations as a consequence of DNA MMR deficiency. In contrast, the adenoma-carcinoma sequence is not a major pathway in gastric carcinogenesis. The pathogenesis of gastric carcinoma is complex and multifactorial, with the importance of $H$. pylori infection varying in different populations. Therefore, the impact of MSI might be lower for GC than for CRC, although the role of MSI in GC is still unclear.
Table 4 Multivariate analysis of risk factors for synchronous and metachronous colorectal cancer in patients with gastric cancer

\begin{tabular}{llll}
\hline Variables & OR & $95 \%$ CI & $P$ value \\
\hline $\begin{array}{l}\text { Age (years) } \\
<63\end{array}$ & 1 & & \\
$\geq 63$ & 5.881 & $3.083-11.221$ & $<\mathbf{0 . 0 0 1}$ \\
Gender & & & \\
$\begin{array}{l}\text { Female } \\
\text { Male }\end{array}$ & 1 & & $\mathbf{0 . 0 0 9}$ \\
p53 overexpression & 2.933 & $1.307-6.584$ & \\
Absent & 1 & & 0.220 \\
Present & 1.392 & $0.821-2.361$ & \\
\hline
\end{tabular}

Numbers in bold type indicate statistical significance

$O R$ odds ratio, $C I$ confidence interval

In Lynch syndrome-associated cancers, MMR deficiency results from a germline mutation affecting the DNA MMR genes (MLH1, MSH2, MSH6, or PMS2). In the current study, patients with MSI-H were not investigated 
for immunohistochemistry of MMR gene proteins and/or second-step tumor testing strategies (MLH1 promoter methylation or BRAF mutation testing). In fact, most MSI$\mathrm{H}$ CRCs are sporadic. In addition, patients who had a family history of CRC were not included in this study, and four patients with MSI-H CRC were older than 73 years at diagnosis and did not have cancer in organs other than the stomach, so it was not necessary to perform further testing according to the revised Bethesda guidelines [36]. Consequently, it is unlikely that a patient with Lynch syndrome was involved in the present study.

The p53 tumor suppressor gene appears to play a pivotal role in human carcinogenesis, and p53 is the most commonly mutated gene in human cancer, with alterations occurring in at least $50 \%$ of human malignancies. Normally, wild-type p53 regulates cell cycle arrest, DNA repair, and apoptosis in response to oncogenic stress. In cells in the early $G_{1}$ phase, p53 triggers a checkpoint blocking further progression through the cell cycle, allowing the damaged DNA to be repaired before the cell enters the $\mathrm{S}$ phase [37]. If the DNA damage cannot be repaired, p53 induces apoptosis [38]. Therefore, direct mutations of the p53 gene or a loss of p53 function by its regulators allows a cell with damaged DNA to escape from normal growth, resulting in cancer development [39]. Because of the increased half-life of the mutant p53 protein compared with the wild-type p53, immunochemical overexpression of p53 protein in tumors has been interpreted as a surrogate for p53 mutation. In the present study, overexpression of p53 was significantly more common in GC patients with $\mathrm{CRC}$ compared to those without $\mathrm{CRC}$, but it was not an independent risk factor for $\mathrm{CRC}$ in $\mathrm{GC}$ according to the results of multivariate analysis. As there is no report on the relationship of CRC in GC to p53 overexpression, these results of our investigation are important and require further study in a large population.

Another hypothesis for the development of CRC in GC patients is related to environmental factors such as $H$. pylori infection. Several previous investigations have studied the relationship between $H$. pylori and colonic neoplasms. A recent German study with 156,000 subjects showed that $H$. pylori gastritis increased the risk for CRC 2.35-fold [40]. In addition, H. pylori was found to increase the risk of colorectal adenoma in a Korean population [41, 42]. There are several speculations about this association. It has been assumed that $H$. pylori infection of the gastric mucosa leads to increased levels of serum gastrin, which may act as a growth-promoting hormone on the colon mucosa $[43,44]$. H. pylori could act on the colon mucosa itself and affect polyp growth or promote the development of mucosa dysplasia. While $H$. pylori is generally considered to simply migrate through the colon, there is a small possibility that this bacterium could colonize the colon. In the present study, there was no significant difference in $H$. pylori infection status between GC patients with and without $\mathrm{CRC}$, although the number of patients who underwent $H$. pylori infection tests was relatively small. Furthermore, $H$. pylori-infection-negative GC is extremely rare in Korea [45], so it is difficult to ascertain the association between CRC and $H$. pylori infection.

GC and CRC are biologically heterogeneous diseases that can develop via a number of distinct pathways involving different combinations of genetic and epigenetic changes. The biologic distinctions between GC and CRC resulting from different etiologic pathways can make it difficult to evaluate the association between these two cancer types.

There are a few limitations of this study. There may be a bias in the current study due to the retrospective nature of the analyses. However, the patients in this study came from a GC cohort that had been collected prospectively and the large number of patients may have minimized the effect of selection bias. In addition, we did not exclude patients with a history of colorectal adenomatous polyps. Only GCs treated using endoscopic and surgical resection were included in this study. Advanced-stage GCs that underwent palliative chemotherapy or conservative treatment might have been selectively excluded, so the incidence may have been underestimated.

In conclusion, the incidence of CRC in patients with GC was $6.4 \%$ and the prevalence of synchronous GC was $4.4 \%$. Regular colonoscopies on patients who have been diagnosed with GC are important, particularly for those who are $\geq 63$ years old and men. However, p53 overexpression or MSI were not predictors for synchronous and metachronous CRC in GC. Large-scale prospective epidemiologic studies or studies on molecular pathogenesis are needed to further investigate the common risk factors for GC and CRC.

Acknowledgments This work was supported by a National Research Foundation (NRF) of Korea grant for the Global Core Research Center (GCRC) funded by the Korean government (MSIP) (no. 2011-0030001). The authors thank the Division of Statistics of the Medical Research Collaborating Center at Seoul National University Bundang Hospital for their help with the statistical analyses.

\section{Compliance with ethical standards}

Conflict of interest The authors declare that they have no conflict of interest.

Human rights statement and informed consent All procedures followed were in accordance with the ethical standards of the responsible committee on human experimentation (institutional and national) and with the Helsinki Declaration of 1964 and later versions of it. Informed consent or a substitute for it was obtained from all patients before they were included in the study. 


\section{References}

1. Ikeda Y, Saku M, Kawanaka H, Nonaka M, Yoshida K. Features of second primary cancer in patients with gastric cancer. Oncology. 2003;65:113-7.

2. Dinis-Ribeiro M, Lomba-Viana H, Silva R, Moreira-Dias L, Lomba-Viana R. Associated primary tumors in patients with gastric cancer. J Clin Gastroenterol. 2002;34:533-5.

3. Cho I, An JY, Kwon IG, Choi YY, Cheong JH, Hyung WJ, et al. Risk factors for double primary malignancies and their clinical implications in patients with sporadic gastric cancer. Eur J Surg Oncol. 2014;40:338-44.

4. Eom BW, Lee HJ, Yoo MW, Cho JJ, Kim WH, Yang HK, et al. Synchronous and metachronous cancers in patients with gastric cancer. J Surg Oncol. 2008;98:106-10.

5. Ojima T, Iwahashi M, Nakamori M, Nakamura M, Katsuda M, Iida $\mathrm{T}$, et al. Is preoperative colonoscopy necessary for patients undergoing gastric cancer surgery? Ann Surg Oncol. 2014;21(Suppl 3):S379-84.

6. Suzuki A, Koide N, Takeuchi D, Okumura M, Ishizone S, Suga $\mathrm{T}$, et al. Prevalence of synchronous colorectal neoplasms in surgically treated gastric cancer patients and significance of screening colonoscopy. Dig Endosc. 2014;26:396-402.

7. Kim HO, Hwang SI, Yoo CH, Kim H. Preoperative colonoscopy for patients with gastric adenocarcinoma. J Gastroenterol Hepatol. 2009;24:1740-4.

8. Park DI, Park SH, Yoo TW, Kim HS, Yang SK, Byeon JS, et al. The prevalence of colorectal neoplasia in patients with gastric cancer: a Korean Association for the Study of Intestinal Disease (KASID) study. J Clin Gastroenterol. 2010;44:102-5.

9. Saito S, Hosoya Y, Togashi K, Kurashina K, Haruta H, Hyodo M, et al. Prevalence of synchronous colorectal neoplasms detected by colonoscopy in patients with gastric cancer. Surg Today. 2008;38:20-5.

10. Lynch HT, Lynch PM, Lanspa SJ, Snyder CL, Lynch JF, Boland CR. Review of the Lynch syndrome: history, molecular genetics, screening, differential diagnosis, and medicolegal ramifications. Clin Genet. 2009;76:1-18.

11. Kato M, Asaka M, Shimizu Y, Nobuta A, Takeda H, Sugiyama T, et al. Relationship between Helicobacter pylori infection and the prevalence, site and histological type of gastric cancer. Aliment Pharmacol Ther. 2004;20(Suppl 1):85-9.

12. Arnold CN, Goel A, Blum HE, Boland CR. Molecular pathogenesis of colorectal cancer: implications for molecular diagnosis. Cancer. 2005;104:2035-47.

13. Huxley RR, Ansary-Moghaddam A, Clifton P, Czernichow S, Parr CL, Woodward M. The impact of dietary and lifestyle risk factors on risk of colorectal cancer: a quantitative overview of the epidemiological evidence. Int J Cancer. 2009;125:171-80.

14. Low S, Chin MC, Ma S, Heng D, Deurenberg-Yap M. Rationale for redefining obesity in Asians. Ann Acad Med Singapore. 2009;38:66-9.

15. Edge SB, Compton CC. The American Joint Committee on Cancer: the 7th edition of the AJCC cancer staging manual and the future of TNM. Ann Surg Oncol. 2010;17:1471-4.

16. Oh JR, Kim DW, Lee HS, Lee HE, Lee SM, Jang JH, et al. Microsatellite instability testing in Korean patients with colorectal cancer. Fam Cancer. 2012;11:459-66.

17. Boland CR, Thibodeau SN, Hamilton SR, Sidransky D, Eshleman JR, Burt RW, et al. A National Cancer Institute Workshop on Microsatellite Instability for cancer detection and familial predisposition: development of international criteria for the determination of microsatellite instability in colorectal cancer. Cancer Res. 1998;58:5248-57.
18. Lee HK, Lee HS, Yang HK, Kim WH, Lee KU, Choe KJ, et al. Prognostic significance of $\mathrm{Bcl}-2$ and $\mathrm{p} 53$ expression in gastric cancer. Int J Colorectal Dis. 2003;18:518-25.

19. Byeon JS, Yang SK, Kim TI, Kim WH, Lau JY, Leung WK, et al. Colorectal neoplasm in asymptomatic Asians: a prospective multinational multicenter colonoscopy survey. Gastrointest Endosc. 2007;65:1015-22.

20. Choe JW, Chang HS, Yang SK, Myung SJ, Byeon JS, Lee D, et al. Screening colonoscopy in asymptomatic average-risk Koreans: analysis in relation to age and sex. J Gastroenterol Hepatol. 2007;22:1003-8.

21. Yoo HM, Gweon TG, Seo HS, Shim JH, Oh SI, Choi MG, et al. Role of preoperative colonoscopy in patients with gastric cancer: a case control study of the prevalence of coexisting colorectal neoplasms. Ann Surg Oncol. 2013;20:1614-22.

22. Hemminki K, Sundquist J, Bermejo JL. How common is familial cancer? Ann Oncol. 2008;19:163-7.

23. Lengauer C, Kinzler KW, Vogelstein B. Genetic instability in colorectal cancers. Nature. 1997;386:623-7.

24. Uchino S, Tsuda H, Noguchi M, Yokota J, Terada M, Saito T, et al. Frequent loss of heterozygosity at the DCC locus in gastric cancer. Cancer Res. 1992;52:3099-102.

25. Nakatsuru S, Yanagisawa A, Ichii S, Tahara E, Kato Y, Nakamura $\mathrm{Y}$, et al. Somatic mutation of the APC gene in gastric cancer: frequent mutations in very well differentiated adenocarcinoma and signet-ring cell carcinoma. Hum Mol Genet. 1992;1:559-63.

26. Kataoka M, Okabayashi T, Johira H, Nakatani S, Nakashima A, Takeda A, et al. Aberration of p53 and DCC in gastric and colorectal cancer. Oncol Rep. 2000;7:99-103.

27. Fang DC, Luo YH, Yang SM, Li XA, Ling XL, Fang L. Mutation analysis of APC gene in gastric cancer with microsatellite instability. World J Gastroenterol. 2002;8:787-91.

28. Li M, Liu W, Zhu YF, Chen YL, Zhang BZ, Wang R. Correlation of COX-2 and K-ras expression to clinical outcome in gastric cancer. Acta Oncol. 2006;45:1115-9.

29. Tanaka M, Omura K, Watanabe Y, Oda Y, Nakanishi I. Prognostic factors of colorectal cancer: K-ras mutation, overexpression of the p53 protein, and cell proliferative activity. J Surg Oncol. 1994;57:57-64.

30. Boland CR, Goel A. Microsatellite instability in colorectal cancer. Gastroenterology. 2010;138(2073-87):e3.

31. Veigl ML, Kasturi L, Olechnowicz J, Ma AH, Lutterbaugh JD, Periyasamy S, et al. Biallelic inactivation of hMLH1 by epigenetic gene silencing, a novel mechanism causing human MSI cancers. Proc Natl Acad Sci USA. 1998;95:8698-702.

32. Hampel H, Stephens JA, Pukkala E, Sankila R, Aaltonen LA, Mecklin JP, et al. Cancer risk in hereditary nonpolyposis colorectal cancer syndrome: later age of onset. Gastroenterology. 2005;129:415-21.

33. Ottini L, Falchetti M, Lupi R, Rizzolo P, Agnese V, Colucci G, et al. Patterns of genomic instability in gastric cancer: clinical implications and perspectives. Ann Oncol. 2006;17(Suppl 7):vii97-102.

34. Falchetti M, Saieva C, Lupi R, Masala G, Rizzolo P, Zanna I, et al. Gastric cancer with high-level microsatellite instability: target gene mutations, clinicopathologic features, and long-term survival. Hum Pathol. 2008;39:925-32.

35. Yun HR, Yi LJ, Cho YK, Park JH, Cho YB, Yun SH, et al. Double primary malignancy in colorectal cancer patients-MSI is the useful marker for predicting double primary tumors. Int $\mathrm{J}$ Colorectal Dis. 2009;24:369-75.

36. Umar A, Boland CR, Terdiman JP, Syngal S, de la Chapelle A, Ruschoff $\mathrm{J}$, et al. Revised Bethesda guidelines for hereditary nonpolyposis colorectal cancer (Lynch syndrome) and microsatellite instability. J Natl Cancer Inst. 2004;96:261-8. 
37. Levine AJ, Momand J, Finlay CA. The p53 tumour suppressor gene. Nature. 1991;351:453-6.

38. Haupt S, Berger M, Goldberg Z, Haupt Y. Apoptosis-the p53 network. J Cell Sci. 2003;116:4077-85.

39. Jang BG, Kim WH. Molecular pathology of gastric carcinoma. Pathobiology. 2011;78:302-10.

40. Sonnenberg A, Genta RM. Helicobacter pylori is a risk factor for colonic neoplasms. Am J Gastroenterol. 2013;108:208-15.

41. Hong SN, Lee SM, Kim JH, Lee TY, Kim JH, Choe WH, et al. Helicobacter pylori infection increases the risk of colorectal adenomas: cross-sectional study and meta-analysis. Dig Dis Sci. 2012;57:2184-94.

42. Nam KW, Baeg MK, Kwon JH, Cho SH, Na SJ, Choi MG. Helicobacter pylori seropositivity is positively associated with colorectal neoplasms. Korean J Gastroenterol. 2013;61:259-64.
43. Georgopoulos SD, Polymeros D, Triantafyllou K, Spiliadi C, Mentis A, Karamanolis DG, et al. Hypergastrinemia is associated with increased risk of distal colon adenomas. Digestion. 2006;74:42-6.

44. Jones M, Helliwell P, Pritchard C, Tharakan J, Mathew J. Helicobacter pylori in colorectal neoplasms: is there an aetiological relationship? World J Surg Oncol. 2007;5:51.

45. Kim HJ, Hwang SW, Kim N, Yoon H, Shin CM, Park YS, et al. Helicobacter pylori and molecular markers as prognostic indicators for gastric cancer in Korea. J Cancer Prev. 2014;19:56-67. 